Research Article

\title{
Effect of Sugar Palm Fiber Surface on Interfacial Bonding with Natural Sago Matrix
}

\author{
H. Mardin, ${ }^{1}$ I. N. G. Wardana, ${ }^{2}$ Pratikto, ${ }^{2}$ Wahyono Suprapto, ${ }^{2}$ and Kusno Kamil $^{1}$ \\ ${ }^{1}$ Department of Mechanical Engineering, Universitas Muslim Indonesia, Makassar, Indonesia \\ ${ }^{2}$ Department of Mechanical Engineering, Brawijaya University, Malang, Indonesia \\ Correspondence should be addressed to Kusno Kamil; kusno.kamil@umi.ac.id
}

Received 13 August 2016; Revised 11 October 2016; Accepted 30 October 2016

Academic Editor: Gianluca Cicala

Copyright (c) $2016 \mathrm{H}$. Mardin et al. This is an open access article distributed under the Creative Commons Attribution License, which permits unrestricted use, distribution, and reproduction in any medium, provided the original work is properly cited.

Palm fibers were immersed in sea water for 1,2,3, and 4 weeks prior to application as reinforcement of green biocomposite. Instead of common resin matrix, natural sago starch was applied as the matrix compound. The immersion treatments had significantly affected fibers surface morphology and interfacial bonds of fiber and the matrix as observed through Scanning Electron Microscopy (SEM). The quality of interfacial bonds became higher by additional duration of the sea water immersion. The best interlocking surfaces of fibers and matrix appeared in the composite with 4-week immersed fibers, indicated by disappearance of gaps between fiber and matrix. The morphology of fibers surface interlocking process was clearly seen during the duration of immersion.

\section{Introduction}

Characteristics of natural fiber are differenced from commercial synthetic fibers in terms of geometry, morphology, and surface profiles. Flax, hemp, and jute are some of the most common natural fibers used for composites reinforcement. Composites made of natural fibers as reinforcement and polymeric-based matrices known as biocomposites or green composites should be more eco-friendly and more degradable $[1,2]$. The increasing awareness of environmental sustainability and natural fibers should contribute to a cleaner environment in today's huge demands of composite products [3]. Boosted by this global green issues, research on various types of natural fibers becomes more popular to reveal their advantages compared to synthetic fibers, including their application possibilities as construction materials and engineering [2, 4-10]. Most of natural fibers consist of high cellulose with difference in particular microstructure. This particular microstructure has strong bonds of intraand intermolecular hydrogen which are various in sizes. The larger the molecule size, the weaker the bond, and the smaller the molecular size, the stronger their bonds [11]. Hence, microstructures affect the tensile strength of fibers.

Natural palm sugar fiber (Arenga pinnata) has been studied elsewhere and potentially applied as reinforcement substance in composite material due to its flexural properties, salt water resistance, and environmentally friendly and relatively high tensile strength. As microstructures of palm sugar fiber consist of $85 \%$ cellulose covering almost the whole fibers surface, the fibril bonds then become stronger [12-16]. Meanwhile, composite matrix is the major impart of biocomposite, yet, rarely discussed due to its limitation in physical characteristics as bonding agent for the composite fibers. Some effort on this biomatrix had been reported by some researchers $[2,17]$ but is still lacking in thermomechanical and hardening issues. When it comes to composite manufacture, most natural fibers are hydrophilic in nature, strongly opposite to the hydrophobic properties of polymeric-based matrices, and result in weak interfacial bond and less tensile strength $[18,19]$. Hence, various efforts to anticipate this shortage by reducing the hydrophilic characteristic have been implemented in many studies. Fiber immersion in types of 
TABLE 1: Palm fibers composition.

\begin{tabular}{lcc}
\hline Element & Oxides & Unit (\%) \\
\hline Silicon & $\mathrm{SiO}_{2}$ & 30.45 \\
Aluminum & $\mathrm{Al}_{2} \mathrm{O}_{3}$ & 21.9 \\
Sodium & $\mathrm{Na}_{2} \mathrm{O}$ & 18.44 \\
Magnesium & $\mathrm{MgO}$ & 9.0 \\
Potassium & $\mathrm{K} 2 \mathrm{O}$ & 0.71 \\
Calcium & $\mathrm{CaO}$ & - \\
Phosphorus & $\mathrm{P}_{2} \mathrm{O}_{5}$ & 5.06 \\
Sulfur & $\mathrm{SO}_{3}$ & 4.74 \\
Others & - & 9.7 \\
\hline & $\mathrm{Total}$ & 100 \\
\hline
\end{tabular}

water or alkaline solutions is some of practices intended to preserve the fiber to be more hydrophobic compatible on polymer matrices [6, 20-23].

Fiber's surface morphology and roughness are crucial for composite reinforcement applications [14]. Their effects on the performance of composites have been investigated by interfacial shear strength of fiber surface roughness [24], where topography of fiber surfaces was affected by immersion, reported somewhere by qualitative observation through Scanning Electron Microscopy [12]. Furthermore, sea water immersion cleans unwanted films off the fiber surface such as lignin, pectin, wax, and dirt (impurities), obtaining relatively uniform surface's topography. Quantitative characteristics of fiber surface can be observed by direct measurement of arithmetic surface roughness which provides information about porosity and roughness [13], while changes on the fiber surfaces can be identified through comparison between immersed (treated) and the untreated fibers. This study observes the effects of sea water on fiber surface morphology and roughness so that the interface of sugar palm fiber and the bio-based matrix of sago may be improved to be considered as new green biocomposite material. SEM and roughness arithmetic are utilized to analyze the surface morphology and roughness of the fiber surfaces.

\section{Material and Methods}

2.1. Material. Untreated fibers are taken from a minimum 8year-old palm trunks whose composition is shown in Table 1. The sea water compositions at temperature $20^{\circ} \mathrm{C}$ are $88.7 \%$ $\mathrm{NaCl}, 10.8 \% \mathrm{SO}_{3}, 0.3 \%$ carbonate, and others of approx. $0.2 \%$.

2.2. Methods. The sugar palm fibers immersion varied to 1 , 2,3 , and 4 weeks inside a 250-liter plastic container of controlled water salinity, closed lid as protestor from open air contamination. Untreated and treated fibers are fully dried inside oven at $80^{\circ} \mathrm{C}$ for 6 hours and then cut to approx. $4 \mathrm{~mm}$ long for testing on a TESCAN SEM VEGA 3 SB. XRD test was applied on a Rigaku Mini Flex II Desktop to identify contained elements of fibers. Surface roughness is determined by touch sensors attached on Mitutoyo SJ 301 by laying the fiber on the sample preparation glass.
Tensile test of single fiber applies ASTM 3379-75 by universal testing machine LR10K Plus, twin columns with load capacity of $10 \mathrm{kN}$. Fibers are glued on a cardboard which has been formed in accordance with the standard. At both ends of cardboard, clamps are pulled slowly and loaded from zero to the fiber break point while set of computer records the actual stresses and strains.

\section{Result and Discussion}

As shown in Figure 1, surface morphology of fiber is determined by the immersion duration in salt water. Surface of untreated fiber is covered by pectin and impurities, closing the gaps holes on fiber surface (Figure 1(a)). After a week of immersion as seen in Figure 1(b), pectin on fiber surface starts to emerge as water content increases. The sea water immersion then continued to week 2 (Figure 1(c)), when pectin began to stand out and expose most of the fiber surface which then became slightly clearer on week 3 as shown in Figure 1(d). At week 4, fiber surface cleared off all its cover, exposing its rough surface (Figure $1(\mathrm{~d})$ ). Here, impurities and pectin molecules which consist of group $\mathrm{OH}^{-}$were attracted by $\mathrm{Na}^{+}$component of the sea water salt, and the polarity differences tend to bind one to another to form ionic bonds.

3.1. Interfacial Bonding. Interfacial bonds between sago starch matrix and sugar palm fiber are shown in Figure 2. Large surface tension occurred among untreated fiber and the matrix (Figure 2(a)) where the matrix refuses to fuse due to overlaid pectin film on fiber surfaces. In contrast, immersion treatments for the next 1,2 , and 3 weeks slowly reduce surface tension (Figures 2(b)-2(d)) and improve the matrix-fiber bonding as the slits became closer. A strong bond occurs after 4 -week immersion, characterized by slit disappearance and invisible loopholes of interfaces.

This phenomenon is related to the alteration of hydrophobic properties of fibers and promotes reactions of polymerization of the two materials. In addition, fiber's positive ions and negative ions from $\mathrm{NaCl}$ accentuate the bond strength where the matrix envelops the fibers thoroughly. In the meantime, reduction of hemicelluloses and pectin also improved the mechanical interlocking.

3.2. X-Ray Diffractometer. The number of fiber cellulose determines the nature of structure and crystal resulting by X-ray diffractometer as shown in Figure 3. Spectrum of untreated sugar palm fiber (UF) shows two peaks at $2 \theta=16.25^{\circ}$ and $22.35^{\circ}$ with profile curve of small size crystals. In comparison, the spectrum of immersed fibers also shows the same typical crystal index. A consistent emergence phenomenon of crystal peak diffractions occurred as reaction to sea water throughout all duration of immersed fibers, 1 to 4 weeks (I, $1 \mathrm{~W}$ to I, $4 \mathrm{~W}$ ), indicating that the treatment only changes the surface morphology due to reduction of hemicelluloses and pectin without changing the typical small size crystals of the fiber.

3.3. Tensile Strength. The increasing trend of tensile strength of sugar palm fiber is shown on Figure 4. However, result 


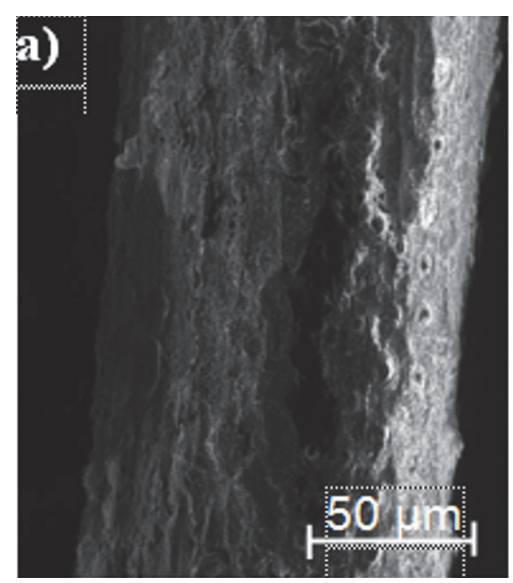

(a)

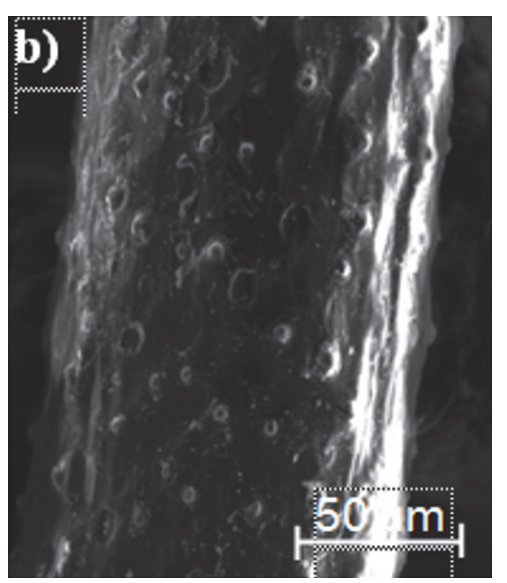

(b)

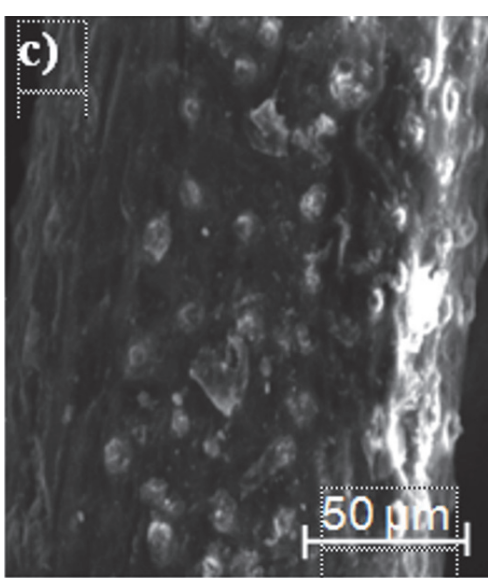

(c)

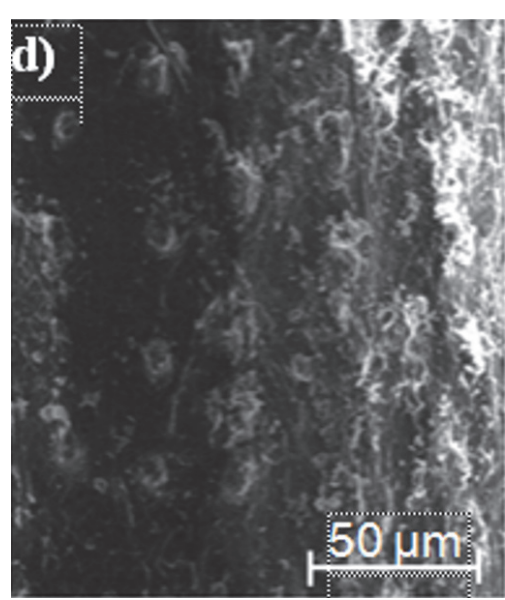

(d)

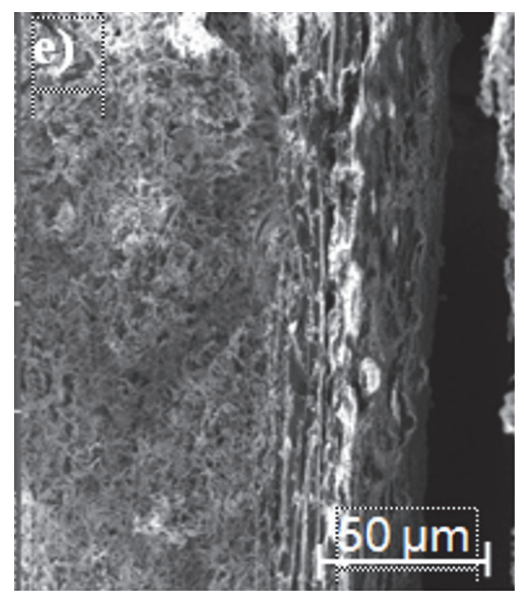

(e)

FIGURE 1: Surface morphology: (a) untreated fiber; (b) 1-week immersion; (c) 2-week immersion; (d) 3-week immersion; (e) 4-week immersion.

TABLE 2: Composition of immersed fibers.

\begin{tabular}{|c|c|c|c|c|c|c|}
\hline Element & Oxide & Green (\%) & $1 \mathrm{~W}(\%)$ & $2 \mathrm{~W}(\%)$ & $3 \mathrm{~W}(\%)$ & $4 \mathrm{~W}(\%)$ \\
\hline Silicon & $\mathrm{SiO}_{2}$ & 30.45 & 35.95 & 44.33 & 33.25 & 40.67 \\
\hline Aluminum & $\mathrm{Al}_{2} \mathrm{O}_{3}$ & 21.9 & 9.49 & 10.38 & 16.76 & 14.23 \\
\hline Sodium & $\mathrm{Na}_{2} \mathrm{O}$ & 18.44 & 14.78 & 16.87 & 15.25 & 12.17 \\
\hline Magnesium & $\mathrm{MgO}$ & 9 & 12.06 & 11.23 & 14.14 & 12.52 \\
\hline Potassium & $\mathrm{K}_{2} \mathrm{O}$ & 0.71 & 1.73 & 0.3 & 1.23 & 1.07 \\
\hline Calcium & $\mathrm{CaO}$ & - & 4.04 & 0.98 & 2.42 & 0.35 \\
\hline Phosphorus & $\mathrm{P}_{2} \mathrm{O}_{5}$ & 5.06 & 7.72 & 7.49 & 7.33 & 8.93 \\
\hline Sulfur & $\mathrm{SO}_{3}$ & 4.74 & 11.54 & 6.82 & 7.74 & 8.32 \\
\hline
\end{tabular}

of tensile stress for 2-week immersion decreases to $\sigma=$ $195.768 \mathrm{~N} / \mathrm{mm}^{2}$, possibly due to the increasing silicon $(\mathrm{Si})$ element from $30.45 \%$ to $44.33 \%$. As the silicon element rises, fibers become more brittle (brittle) and decline the tensile stress result. Further immersion of 3 weeks improves tensile strength to $\sigma=298.646 \mathrm{~N} / \mathrm{mm}^{2}$ and keeps the increasing trend to week 4 by tensile stress $\sigma=420.004 \mathrm{~N} / \mathrm{mm}^{2}$. Increase in tensile strength is made by infiltration of some elements into fibers body (Table 2), causing the cellulose element to increase and developing compound with more interfacial energy which strengthens the immersed fibers.

\section{Conclusions}

Sea water demonstrated its ability to effectively remove the unwanted components on the fiber surfaces such as pectin, wax, and impurities while increasing its adaptability to interlock with the sago matrix compound. Increasing of small 


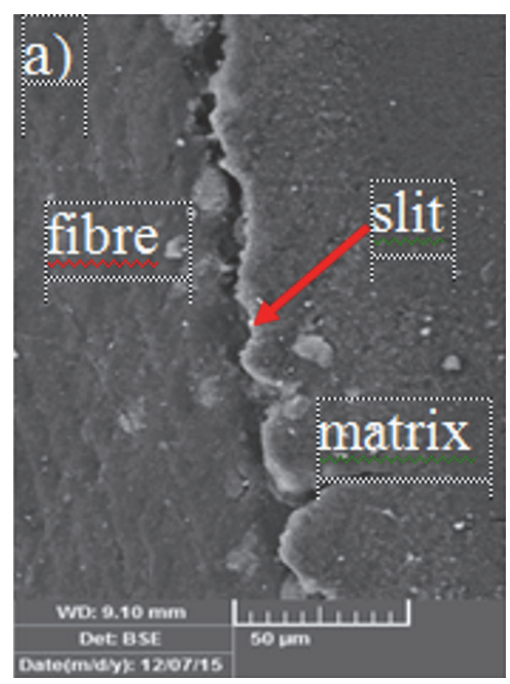

(a)

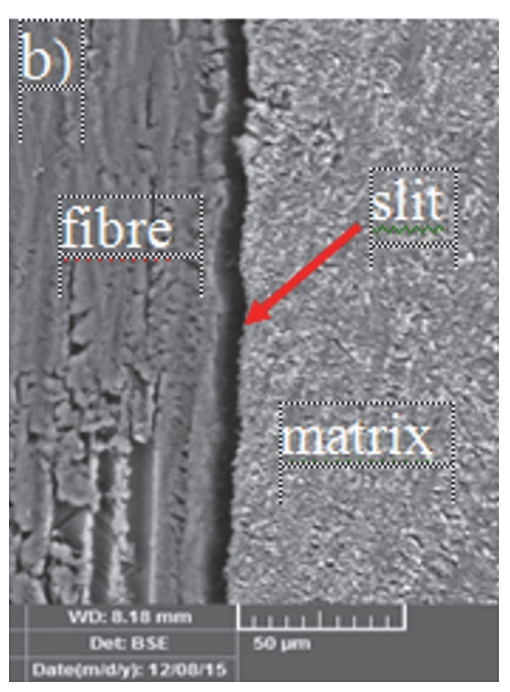

(b)

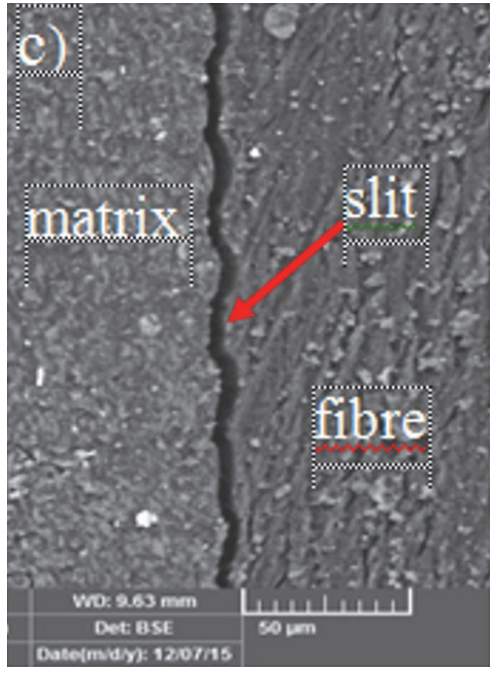

(c)

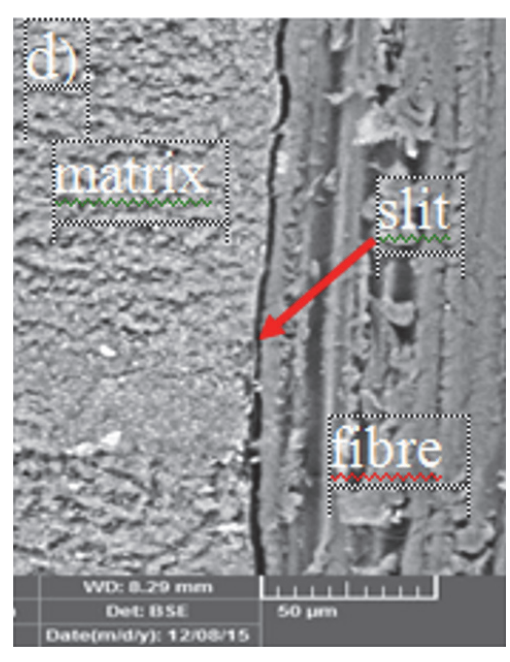

(d)

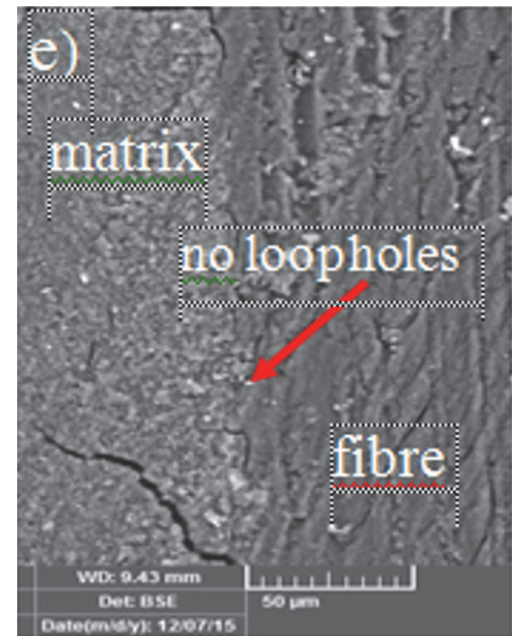

(e)

FIGURE 2: SEM image of matrix-fiber interface: (a) no immersion; (b) 1-week immersion; (c) 2-week immersion; (d) 3-week immersion; (e) 4-week immersion.

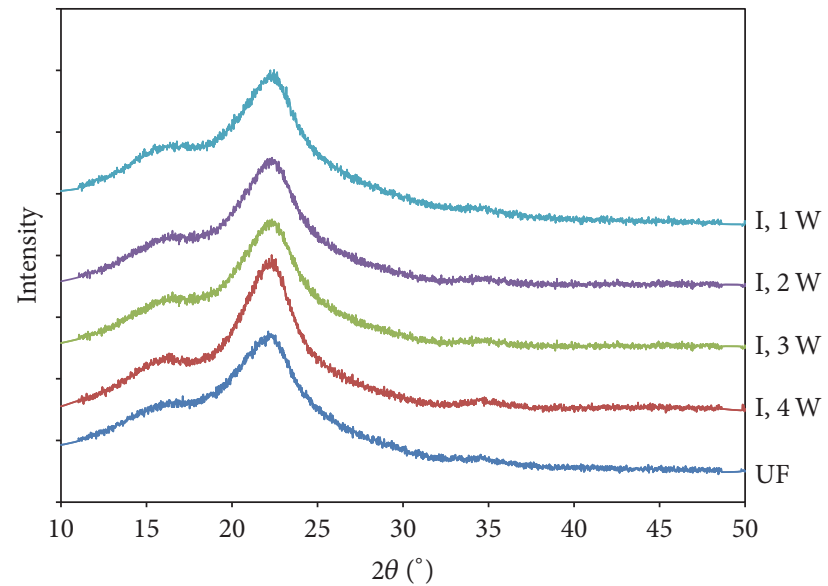

FIGURE 3: X-ray diffractometry.

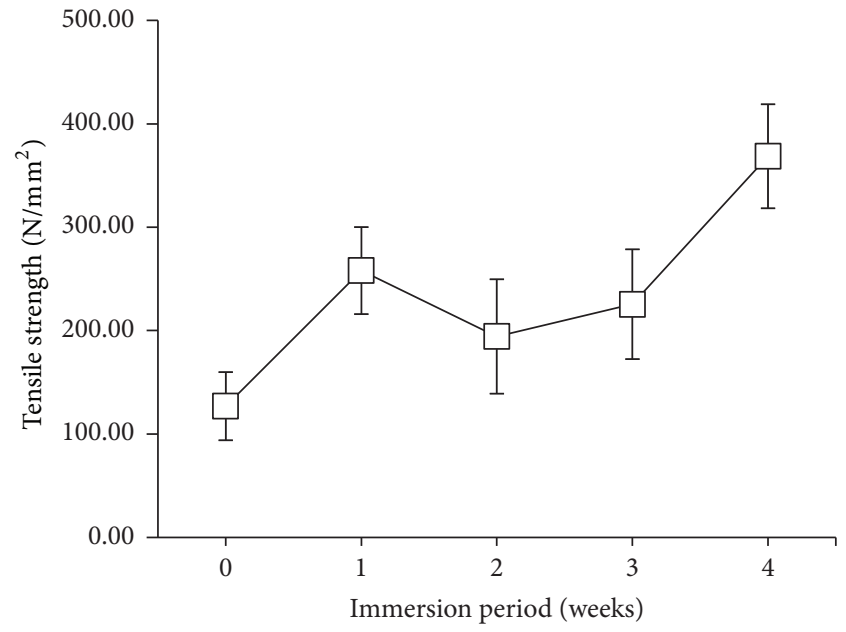

Figure 4: Tensile stress of sugar palm fiber. 
pores on the fiber surface indicates effective morphology may occur over 4 weeks, associated with increasing of surface roughness. The surface morphology of fiber due to sea water treatment has significantly improved the mechanical bonding effect of the sugar palm matrix. Application of bio-based matrix in this study was a breakthrough, as the whole biocomposite material is made of almost $100 \%$ natural substances, making the composite more degradable and environmentally friendly.

\section{Competing Interests}

The authors declare that they have no competing interests.

\section{Acknowledgments}

The authors extend thanks and appreciation to the Dean of the Engineering Faculty and Chairman of the Mechanical Engineering Department of University Muslim Indonesia (UMI), Makassar, on their continuous support throughout the research stages.

\section{References}

[1] H. Mardin, I. N. G. Wardhana, Pratikto, and W. Suprapto, "Effects of sugar palm fiber immersed in sea water toward the palm fiber tensile strength as a composite strengthen," International Journal of Applied Engineering Research, vol. 10, no. 7, pp. 17037-17045, 2015.

[2] A. R. Pai and R. N. Jagtap, "Surface morphology \& mechanical properties of some unique natural fiber reinforced polymer composites-a review," Journal of Materials and Environmental Science, vol. 6, no. 4, pp. 902-917, 2015.

[3] Z. Leman, S. M. Sapuan, M. Azwan, M. M. H. M. Ahmad, and M. A. Maleque, "The effect of environmental treatments on fiber surface properties and tensile strength of sugar palm fiberreinforced epoxy composites," Polymer-Plastics Technology and Engineering, vol. 47, no. 6, pp. 606-612, 2008.

[4] A. Ali, A. B. Sanuddin, and S. Ezzeddin, "The effect of aging on Arenga pinnata fiber-reinforced epoxy composite," Materials and Design, vol. 31, no. 7, pp. 3550-3554, 2010.

[5] W. Liu, J. Huang, N. Wang, and S. Lei, "The influence of moisture content on the interfacial properties of natural palm fiber-matrix composite," Wood Science and Technology, vol. 49, no. 2, pp. 371-387, 2015.

[6] W. Zahari, R. Badri, H. Ardyananta, D. Kurniawan, and F. Nor, "Mechanical properties and water absorption behavior of polypropylene/ijuk fiber composite by using silane treatment," Procedia Manufacturing, vol. 2, pp. 573-578, 2015.

[7] S. Kanking, P. Niltui, E. Wimolmala, and N. Sombatsompop, "Use of bagasse fiber ash as secondary filler in silica or carbon black filled natural rubber compound," Materials \& Design, vol. 41, pp. 74-82, 2012.

[8] S. O. Han and H. Y. Choi, "Morphology and surface properties of natural fiber treated with electron beam," no. 1880, pp. 18801887, 2010.

[9] A. P. Irawan, T. P. Soemardi, K. Widjajalaksmi, and A. H. S. Reksoprodjo, "Gait analysis of the prosthesis prototype made from the natural fiber reinforced composite," in Proceedings of the International Conference APHCI-ERGOFUTURE, pp. 37-43, September 2010.

[10] A. P. Irawan, T. P. Soemardi, K. Widjajalaksmi, and A. H. S. Reksoprodjo, "Tensile and flexural strength of ramie fiber reinforced epoxy composites for socket prosthesis application," International Journal of Mechanical and Materials Engineering, vol. 6, no. 1, pp. 46-50, 2011.

[11] V. Mittal, R. Saini, and S. Sinha, "Natural fiber-mediated epoxy composites-a review," Composites Part B: Engineering, vol. 99, pp. 425-435, 2016.

[12] M. R. Ishak, Z. Leman, S. M. Sapuan, M. Y. Salleh, and S. Misri, "The effect of sea water treatment on the impact and flexural strength of sugar palm fibre reinforced epoxy composites," International Journal of Mechanical and Materials Engineering, vol. 4, no. 3, pp. 316-320, 2009.

[13] M. R. Ishak, S. M. Sapuan, Z. Leman, M. Z. A. Rahman, and U. M. K. Anwar, "Characterization of sugar palm (Arenga pinnata) fibres tensile and thermal properties," Journal of Thermal Analysis and Calorimetry, vol. 109, no. 2, pp. 981-989, 2012.

[14] M. R. Ishak, S. M. Sapuan, Z. Leman, M. Z. A. Rahman, U. M. K. Anwar, and J. P. Siregar, "Sugar palm (Arenga pinnata): its fibres, polymers and composites," Carbohydrate Polymers, vol. 91, no. 2, pp. 699-710, 2013.

[15] M. E. Selamat, O. Sulaiman, R. Hashim et al., "Measurement of some particleboard properties bonded with modified carboxymethyl starch of oil palm trunk," Measurement, vol. 53, pp. 251-259, 2014.

[16] R. S. Singhal, J. F. Kennedy, S. M. Gopalakrishnan, A. Kaczmarek, C. J. Knill, and P. F. Akmar, "Industrial production, processing, and utilization of sago palm-derived products," Carbohydrate Polymers, vol. 72, no. 1, pp. 1-20, 2008.

[17] P. Zierdt, T. Theumer, G. Kulkarni et al., "Sustainable woodplastic composites from bio-based polyamide 11 and chemically modified beech fibers," Sustainable Materials and Technologies, vol. 6, pp. 6-14, 2015.

[18] P. Ali khudhur, O. S. Zaroog, B. A. Khidhir, and Z. S. Radif, "Fracture toughness of sugar palm fiber reinforced epoxy composites," International Journal of Science and Research, vol. 2, no. 12, pp. 273-279, 2013.

[19] C. Ganesan, Y. Pal, R. S. Babu, and K. Kalpit, "Effect of various fibers on mechanical properties of bio," Composite Materials, vol. 6, no. 2, pp. 67-73, 2013.

[20] L. Yan and N. Chouw, "Effect of water, seawater and alkaline solution ageing on mechanical properties of flax fabric/epoxy composites used for civil engineering applications," Construction and Building Materials, vol. 99, pp. 118-127, 2015.

[21] B. M. Pejic, M. M. Kostic, P. D. Skundric, and J. Z. Praskalo, "The effects of hemicelluloses and lignin removal on water uptake behavior of hemp fibers," Bioresource Technology, vol. 99, no. 15, pp. 7152-7159, 2008.

[22] H. M. Akil, M. F. Omar, A. A. M. Mazuki, S. Safiee, Z. A. M. Ishak, and A. Abu Bakar, "Kenaf fiber reinforced composites: a review," Materials \& Design, vol. 32, no. 8-9, pp. 4107-4121, 2011.

[23] N. Saadaoui, A. Rouilly, K. Fares, and L. Rigal, "Characterization of date palm lignocellulosic by-products and self-bonded composite materials obtained thereof," Materials and Design, vol. 50, pp. 302-308, 2013.

[24] S. J. Hinder, C. Lowe, J. T. Maxted, and J. F. Watts, "The morphology and topography of polymer surfaces and interfaces exposed by ultra-low-angle microtomy," Journal of Materials Science, vol. 40, no. 2, pp. 285-293, 2005. 

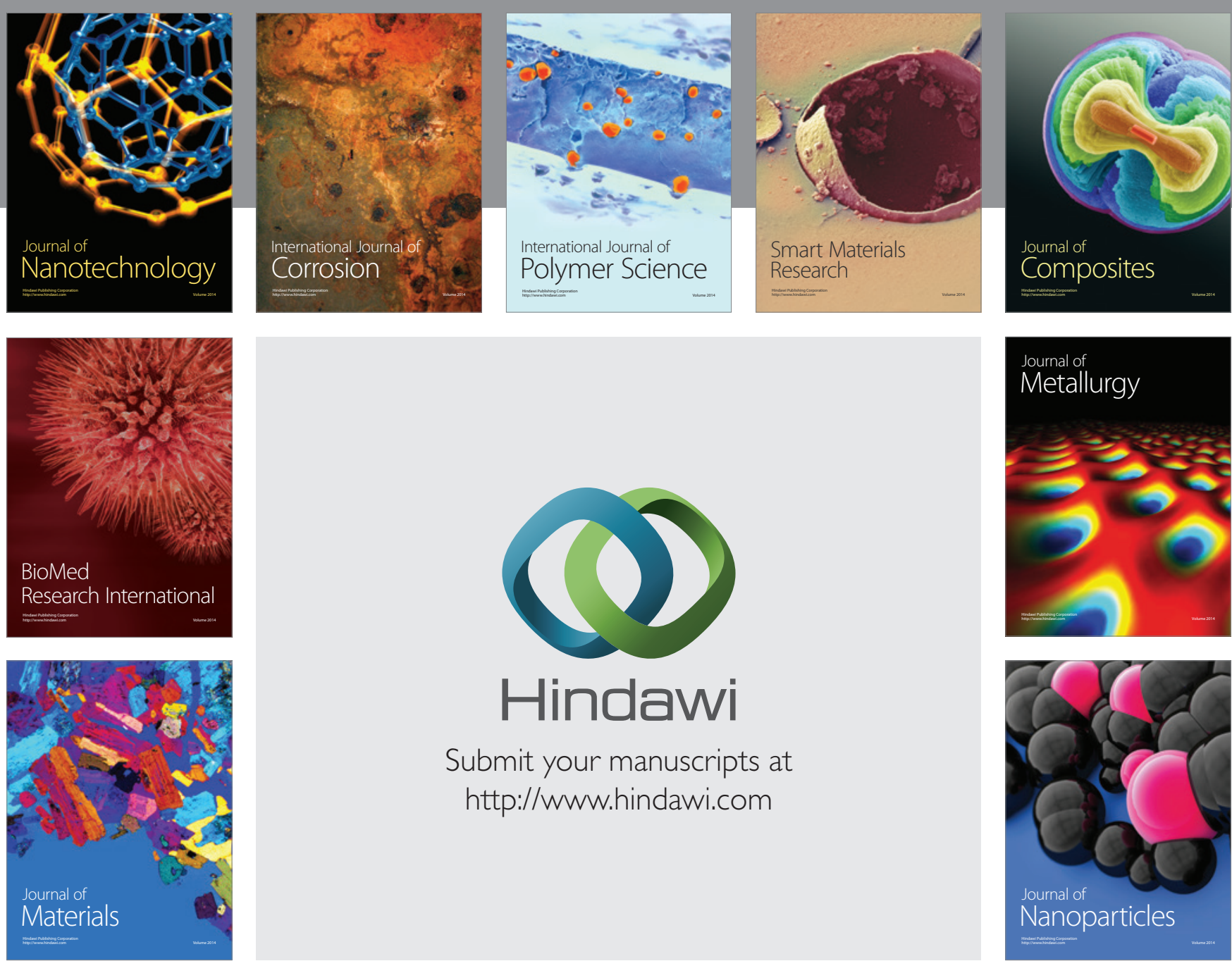

\section{Hindawi}

Submit your manuscripts at

http://www.hindawi.com

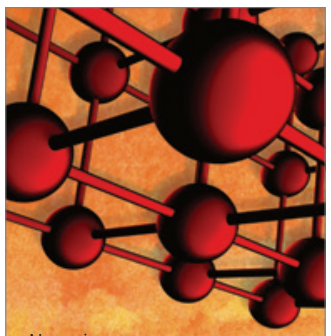

Materials Science and Engineering
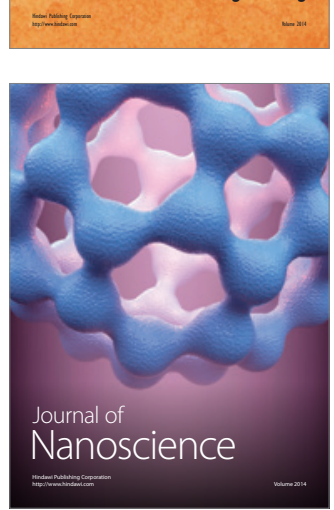
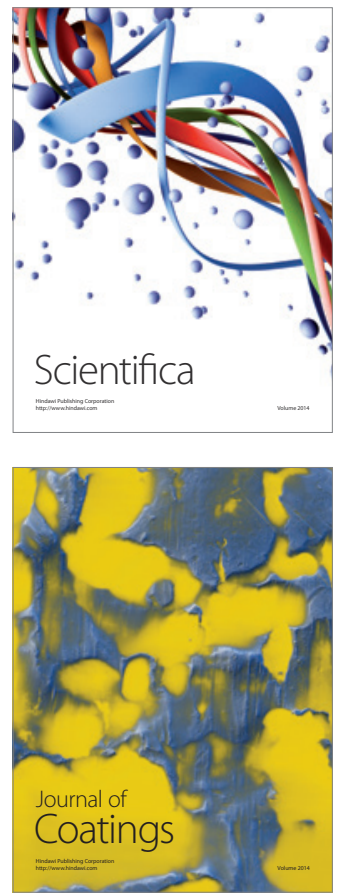
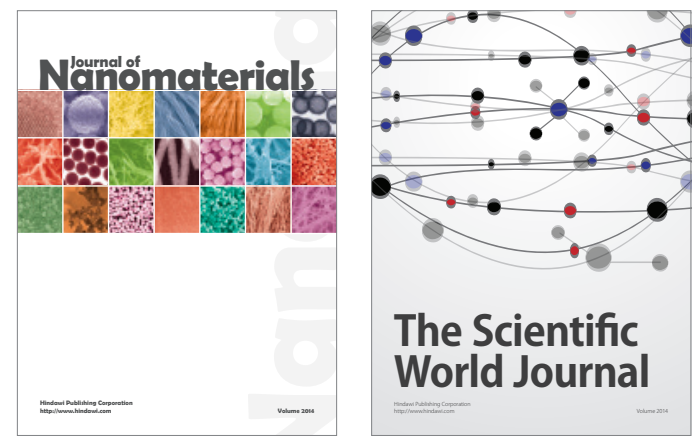

The Scientific World Journal
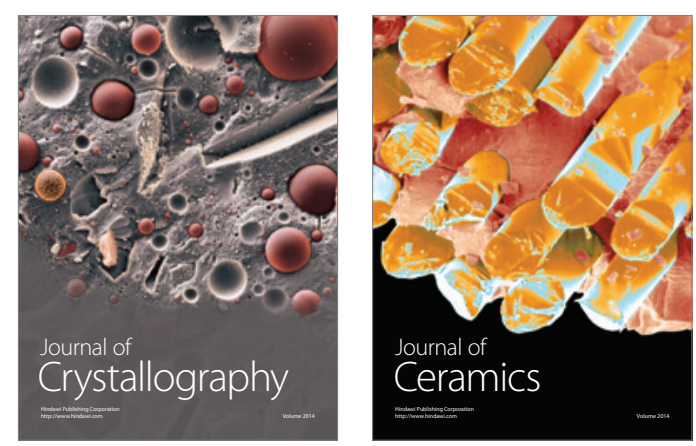
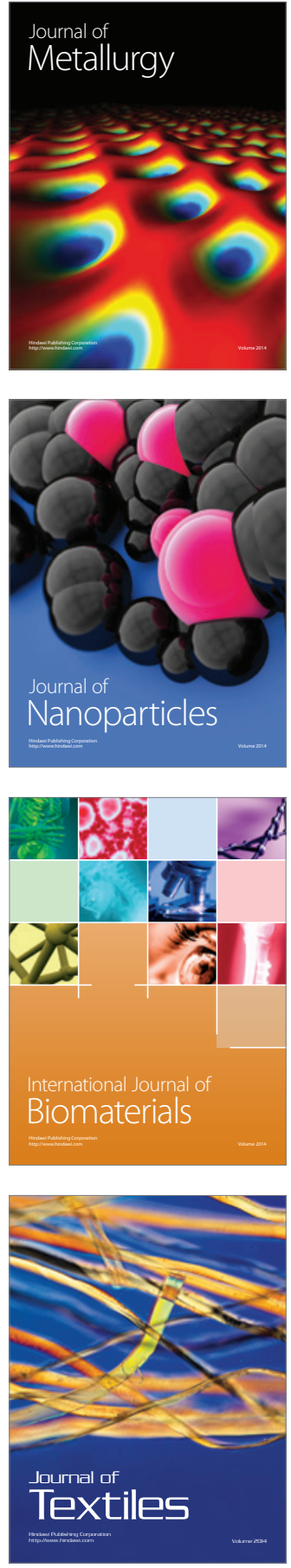